九州大学学術情報リポジトリ

Kyushu University Institutional Repository

\title{
Neuronal major histocompatibility complex class I molecules are implicated in the generation of asymmetries in hippocampal circuitry
}

Kawahara, Aiko

Department of Biology, Faculty of Sciences, Kyushu University

Kurauchi, Shotaro

Department of Biology, Faculty of Sciences, Kyushu University

Fukata, Yuko

Division of Membrane Physiology, National Institute for Physiological Sciences

Mart ínez-Hernández, José

Departamento de Ciencias Médicas, Facultad de Medicina, Instituto de Investigación en Discapacidades Neurológicas (IDINE), Universidad de Castilla-La Mancha | Division of Cerebral Structure, National Institute for Physiological Sciences

他

http://hdl. handle. net/2324/27198

出版情報: The Journal of Physiology. 591 (19)，pp.4777-4791，2013-07-22. Blackwell Publishing バージョン：

権利関係: (C) 2013 The Physiological Society 
Neuronal major histocompatibility complex class I molecules are implicated in the generation of asymmetries in hippocampal circuitry

Aiko Kawahara $^{1}$, Shotaro Kurauchi ${ }^{1}$, Yuko Fukata ${ }^{2}$, José Martínez-Hernández ${ }^{3,4}$, Terumi Yagihashi ${ }^{1}$, Yuya Itadani $^{1}$, Rui Sho ${ }^{1}$, Taiichi Kajiyama ${ }^{1}$, Nao Shinzato ${ }^{1}$, Kenji Narusuye $^{1,5}$, Masaki Fukata ${ }^{2}$, Rafael Luján ${ }^{4}$, Ryuichi Shigemoto ${ }^{3}$, Isao Ito ${ }^{1}$

1) Department of Biology, Faculty of Sciences, Kyushu University, Fukuoka 812-8581, Japan

${ }^{2)}$ Division of Membrane Physiology, National Institute for Physiological Sciences, Okazaki 444-8787, Japan

${ }^{3)}$ Division of Cerebral Structure, National Institute for Physiological Sciences, Okazaki 444-8787, Japan

4) Departamento de Ciencias Médicas, Facultad de Medicina, Instituto de Investigación en Discapacidades Neurológicas (IDINE), Universidad de Castilla-La Mancha, Albacete, Spain

${ }^{5)}$ Current address: Department of Biophysics, Faculty of Pharmaceutical Sciences, Toho University, Funabashi 274-8510, Japan 
Running title: $\mathrm{MHCI}$ is implicated in the generation of hippocampal asymmetry

Key words: Hippocampus, MHCI, Asymmetry

Total number of words: 6547 words

Corresponding author: Isao Ito

Department of Biology, Faculty of Sciences, Kyushu University, Fukuoka 812-8581, Japan.

Email: isitoscb@kyushu-u.org

Phone: +81-92-642-2631 / Fax: +81-92-642-2645

Our manuscript includes:
Abstract: 249 words
Text: $\quad 42$ pages
Figures: $\quad 8$ figures 
Key points summary

- The molecular basis of left-right asymmetries in brain structure and function is a central question in neuroscience.

- We have previously demonstrated that the neuronal circuitry composed of hippocampal pyramidal neurones is asymmetrical depending on the hemispheric origin of presynaptic inputs and cell polarity of the postsynaptic neurone.

- In this study, we analysed the hippocampus of $\beta 2$-microglobulin $(\beta 2 \mathrm{~m})$-deficient mice lacking stable cell surface expression of major histocompatibility complex class I (MHCI), which is known to be important in cellular immunity.

- We found that $\beta 2 \mathrm{~m}$-deficient mice lacked structural and functional asymmetries in hippocampal circuitry, suggesting that MHCI is critical for the generation of hippocampal asymmetry.

- Our results provide a first step in elucidating the cellular process that generates brain asymmetries.

Word count: 125 


\section{Abstract}

Left-right asymmetry is a fundamental feature of higher-order brain function; however, the molecular basis of brain asymmetry has remained unclear. We have recently demonstrated asymmetries in hippocampal circuitry resulting from the asymmetrical allocation of NMDA receptor (NMDAR) subunit GluRe2 (NR2B) in pyramidal cell synapses. This asymmetrical allocation of $\varepsilon 2$ subunits affects the properties of NMDARs and generates two populations of synapses, ' $\varepsilon 2$-dominant' and ' $\varepsilon 2$-nondominant' synapses, according to the hemispheric origin of presynaptic inputs and cell polarity of the postsynaptic neurone. To identify key regulators for generating asymmetries, we analysed the hippocampus of $\beta 2$-microglobulin $(\beta 2 \mathrm{~m})$-deficient mice lacking cell surface expression of major histocompatibility complex class I (MHCI). Although MHCI proteins are well-known in the immune system, accumulating evidence indicates that MHCI proteins are expressed in the brain and are required for activity-dependent refinement of neuronal connections and normal synaptic plasticity. We found that $\beta 2 \mathrm{~m}$ proteins were localised in hippocampal synapses in wild-type mice. NMDA EPSCs in $\beta 2 \mathrm{~m}$-deficient hippocampal synapses receiving inputs from both hemispheres showed similar sensitivity to Ro 25-6981, an $\varepsilon 2$ subunit selective antagonist, with those in ' $\varepsilon 2$-dominant' synapses for both the apical and basal synapses of pyramidal neurones. The structural features of the $\beta 2 \mathrm{~m}$-deficient synapse in addition to the relationship between the stimulation frequency and synaptic plasticity were also comparable to those of ' $\varepsilon 2$-dominant' synapses. These observations indicate that the $\beta 2 \mathrm{~m}$-deficient hippocampus lacks ' $\varepsilon 2$-nondominant' synapses and circuit 
asymmetries. Our findings provide evidence supporting a critical role of MHCI molecules for generating asymmetries in hippocampal circuitry.

\section{Abbreviations}

$\beta \mathrm{ME}, \beta$-Mercaptoethanol; $\beta 2 \mathrm{~m}, \beta 2$-microgrobulin; CNS, central nervous system; Com, commissural; DNQX, 6,7-dinitroquinoxaline-2,3-dione; EPSC, excitatory postsynaptic current; fEPSP, field EPSP; GFP, green fluorescent protein; Hepes, N-2-hydroxyethylpiperazine-N'-2-ethanesulphonic acid; HRP, horseradish peroxidase; Lrd, Left-right dynein; LTD, long-term depression; LTP, long-term potentiation; MHCI, major histocompatibility complex class I; NGS, normal goat serum; NMDAR, $N$-methyl-D-aspartate receptor; PSD, postsynaptic density; Sch, Schaffer collateral; SDS-PAGE, sodium dodecyl sulphate-polyacrylamide gel electrophoresis; TAP, transporter associated with antigen processing; Tris, tris(hydroxymethyl)aminomethane; VHCT, Ventral hippocampal commissure transaction

Introduction

One of the most remarkable features of the brain is that the left and right hemispheres are functionally and anatomically asymmetric. Left-right (L-R) asymmetry (laterality) of the brain, once believed to be a human characteristic, has now been found to be widespread among vertebrates (Geschwind \& Galaburda, 1987; Vallortigara, 2000; Concha et al. 2012). For many years, laterality research has focused on asymmetries in higher-order functions and in gross anatomical structures of the brain, 
whereas recent studies have identified molecular asymmetries in basic structures and functions of simple neuronal networks in the mouse hippocampus (Kawakami et al. 2003; Wu et al. 2005; Kohl et al. 2011) and in the zebrafish habenula (Aizawa et al. 2005; Aizawa et al. 2007).

We have shown that the distribution of NMDA receptor (NMDAR) $\varepsilon 2$ (NR2B) subunits in the wild-type (WT) mouse hippocampus is asymmetrical between synapses formed on the apical and basal dendrites of individual neurones and between synapses formed by inputs from the left and right pyramidal neurones (Fig. 1, WT) (Kawakami et al. 2003; Wu et al. 2005). These asymmetrical allocations of $\varepsilon 2$ subunits affect the properties of NMDARs in hippocampal synapses and generate two populations of synapses. One population consists of ' $\varepsilon 2$-dominant' synapses, in which the NMDAR-mediated EPSCs (NMDA EPSCs) show high sensitivity to Ro 25-6981, an $\varepsilon 2$ subunit selective antagonist (Chizh et al. 2001; Fischer et al. 1997; Mutel et al. 1998), and are often formed on thin dendritic spines (Shinohara et al. 2008). The other population consists of ' $\varepsilon 2$-nondominant' synapses, in which the NMDA EPSCs are less sensitive to Ro 25-6981, and are more frequently formed on large mushroom-type spines. In addition, postnatal development of synaptic plasticity in ' $\varepsilon 2$-dominant' synapses is earlier than in ' $\varepsilon 2$-nondominant' synapses (Kawakami et al. 2003). These two populations of synapses are located asymmetrically in hippocampal circuitry depending on the hemispheric origin of presynaptic inputs (referred to as L-R asymmetry) and cell polarity of the postsynaptic neurone (referred to as apical-basal asymmetry) (Fig. 1, WT). 
By using $\varepsilon 2$ asymmetry as an index for detecting abnormalities in the L-R asymmetry of the brain, we examined the iv mouse hippocampus (Kawakami et al. 2008). $I v$ is a spontaneous mouse mutant that has a mutation in the gene encoding the motor protein Left-right dynein (Lrd) (Hummel \& Chapman, 1959; Supp et al. 1997). The mutated $\mathrm{Lrd}$ causes immotility of nodal cilia and thus fails to produce nodal flow in embryos, resulting in randomised laterality of visceral organs (Nonaka et al. 2002; Okada et al. 1999; Supp et al. 1999). Fifty percent of $i v$ homozygous (iv/iv) mice exhibit reversed asymmetry (situs inversus), whereas the rest are normal (situs solitus). As with WT mice, the iv mouse hippocampus contains both ' $\varepsilon 2$-dominant' and ' $\varepsilon 2$-nondominant' synapses, and develops apical-basal asymmetry of individual neurones normally. However, the iv mouse hippocampus lacks L-R asymmetry; it exhibits right isomerism (bilateral right-sidedness) in the synaptic distribution of the $\varepsilon 2$ subunit, irrespective of the laterality of visceral organs (Fig. 1, iv) (Kawakami et al. 2008). In behavioural experiments designed for examining reference and working memories, the $i v$ mouse showed deficits in the acquisition of spatial reference memory and retention of working memory, suggesting that NMDAR-based asymmetry in hippocampal circuitry is critical for some aspects of higher-order brain functions (Goto et al. 2010).

In the present study, we sought to identify a key regulator required for the generation of $\mathrm{L}-\mathrm{R}$ and apical-basal asymmetries in hippocampal circuitry. Among many possible candidates, we have focused on major histocompatibility complex class I (MHCI), specifically, on its nonimmune functions in the brain (Shatz, 2009; Boulanger 
\& Shatz, 2004; Fourgeaud \& Boulanger, 2010). MHCI family members are well known for their roles in cellular immunity. In the immune system, MHCI molecules act in the discrimination of self- versus non-self-proteins. The MHCI gene family includes $>70$ members in rodents (Fischer-Lindahl, 1997). The proteins encoded are heavy chains comprising the largest portion of the MHCI protein complex. Functional MHCI molecules are trimeric proteins composed of a transmembrane heavy chain, a soluble $\beta 2$-microglobulin $(\beta 2 \mathrm{~m})$ light chain, and a 9-11 amino acid peptide antigen generated from proteosomal degradation (Bijlmakers \& Ploegh, 1993). For most MHCI proteins, cell surface expression of the heavy chain only occurs if the $\beta 2 \mathrm{~m}$ and peptide are bound to the heavy chain (Zijlstra et al. 1990; Vankaer et al. 1992). In their absence, MHCI fails to be trafficked to the plasma membrane (Neefjes \& Momburg, 1993; Spiliotis et al. 2002; Williams et al. 1989). Although MHCI was thought to be absent in the healthy brain, recent studies have revealed MHCI expression in subsets of neurones, including the cerebral cortex, hippocampus (Needleman et al. 2010; Corriveau et al. 1998; Huh et al. 2000), motoneurones (Linda et al. 1999; Oliveira et al. 2004), and the mouse vomeronasal organ (Ishii \& Mombaerts, 2008; Dulac \& Torello, 2003; Loconto et al. 2003). Furthermore, accumulating evidence indicates that MHCI molecules regulate activity-dependent refinement of visual nerve connections, synaptic plasticity in hippocampal and cerebellar slices, and synaptic transmission in dissociated hippocampal cultures (Corriveau et al. 1998; Huh et al. 2000; Goddard et al. 2007; Datwani et al. 2009; McConnell et al. 2009; Glynn et al. 2011; Ribic et al. 2010). Given this evidence, we hypothesised that MHCI regulates the generation of 
asymmetries in neuronal networks; thus, we examined the effects of MHCI deficiency on hippocampal asymmetry. Because numerous MHCI genes may be expressed in hippocampal pyramidal neurones, we studied $\beta 2 \mathrm{~m}$-deficient mice defective in stable cell surface expression of MHCI. We conducted biochemical, electrophysiological, and morphological analyses using the $\beta 2 \mathrm{~m}$-deficient mouse hippocampus and found that the functional and structural characteristics of $\beta 2 \mathrm{~m}$-deficient hippocampal synapses were very similar to those of ' $\varepsilon 2$-dominant' synapses, and furthermore, that the hippocampal circuitry of $\beta 2 \mathrm{~m}$-deficient mice lost both L-R and apical-basal asymmetries. Our data suggest that MHCI molecules play a critical role in the generation of hippocampal asymmetry.

Methods

Animals

C57BL/6 mice were purchased from Kyudo (Fukuoka, Japan). The $\beta 2 \mathrm{~m}$-deficient (B6.129P2-B2 ${ }^{t m l U n c}$, stock number 002087) mice were purchased from The Jackson Laboratory (Bar Harbor, ME, USA). The iv (SI/Col $\times$ C57BL/6J hybrid) mice were donated by Prof. H. Hamada (Osaka University, Japan). Animals were bred and maintained at the Faculty of Sciences, Kyushu University. For the following experiments, animals were decapitated under deep sevoflurane anaesthesia, and their brains were quickly removed. All experiments were performed under the guidance of Animal Experiments in Faculty of Sciences, Kyushu University and the National Institute for Physiological Sciences. 
Subcellular fractionation

The method for subcellular fractionation was performed as described previously (Carlin et al. 1980). In brief, hippocampal tissue was homogenised in homogenisation buffer (0.32 M sucrose, $10 \mathrm{mM}$ Hepes-NaOH [pH 7.4], and $50 \mu \mathrm{g} \mathrm{ml}^{-1}$ PMSF) followed by multiple centrifugation steps. The homogenate was centrifuged for $10 \mathrm{~min}$ at $1000 \mathrm{~g}$ to remove the crude nuclear fraction (P1). The supernatant (S1) was centrifuged at $9000 \mathrm{~g}$ for $15 \mathrm{~min}$ to produce a pellet (P2) and supernatant (S2). The S2 was centrifuged at $100,000 \mathrm{~g}$ for $1 \mathrm{~h}$ to produce a pellet (P3, microsomal fraction) and supernatant (S3). The P2 fraction was resuspended in the homogenisation buffer. Discontinuous sucrose gradients containing $3 \mathrm{ml}$ of the resuspended P2 material, and 3 $\mathrm{ml}$ each of $0.8 \mathrm{M}, 1.0 \mathrm{M}$, and 1.2 $\mathrm{M}$ sucrose solutions in $10 \mathrm{mM}$ Hepes- $\mathrm{NaOH}(\mathrm{pH} 7.4)$ were run for $2 \mathrm{~h}$ at 58,000 g (SW41 rotor, Beckman Coulter, Brea, CA, USA). The band between 1.0 M and 1.2 M sucrose was obtained as a synaptosome fraction (Syn). This synaptosome fraction was extracted with ice-cold $0.5 \%$ Triton $\mathrm{X}-100,0.16 \mathrm{M}$ sucrose and $6 \mathrm{mM}$ Tris- $\mathrm{HCl}(\mathrm{pH} \mathrm{8.0)}$, and then centrifuged at 32,800 g for $20 \mathrm{~min}$ to separate the soluble (Sol) and insoluble fractions (postsynaptic density 1 [PSD1]). PSD1 was resuspended in $0.5 \%$ Triton $\mathrm{X}-100,0.16 \mathrm{M}$ sucrose, and $6 \mathrm{mM}$ Tris- $\mathrm{HCl}(\mathrm{pH} 8.0)$ and centrifuged at 200,000 $\mathrm{g}$ for $1 \mathrm{~h}$ to produce a pellet (PSD2).

Western blot analysis 
Proteins were suspended in SDS-PAGE sample buffer $(62.5 \mathrm{mM}$ Tris-HCl $[\mathrm{pH}$ 6.8 $], 10 \%$ glycerol, $2 \%$ SDS, and $0.001 \%$ bromophenol blue) with $2 \%$ $\beta$-Mercaptoethanol $(\beta \mathrm{ME})$ and boiled at $100^{\circ} \mathrm{C}$ for $5 \mathrm{~min}$. Equal amounts of protein of each fraction $(20 \mu \mathrm{g}$ each for $\beta 2 \mathrm{~m}, 10 \mu \mathrm{g}$ each for PSD-95) were subjected to SDS-PAGE. A $10-16 \%$ gradient gel for $\beta 2 \mathrm{~m}$, and an $8 \%$ gel for PSD-95 were used. After protein separation by electrophoresis, samples were transferred to Immobilon-P membrane (Millipore, Bedford, MA, USA) followed by immunoblotting. We used the following primary antibodies: rabbit monoclonal anti- $\beta 2 \mathrm{~m}(1 / 500$, ab75853, Abcam) and mouse monoclonal anti-PSD-95 (1/500, MA1-046, Thermo Scientific Pierce). The following HRP-conjugated secondary antibodies were used: anti-rabbit IgG (NA934) and anti-mouse IgG (NA931) (GE Healthcare, Buckinghamshire, England). To detect specific signals, we used Amersham ECL Plus ${ }^{\mathrm{TM}}$ Western Blotting detection reagents (GE Healthcare).

Ventral hippocampal commissure transection (VHCT)

To examine synapses made by ipsilateral Sch fibres, the VHC was transected 5 days before electrophysiological recording (Kawakami et al. 2003; Wu et al. 2005; Kawakami et al. 2008). $\beta 2 \mathrm{~m}$-deficient mice (C57BL/6 genetic background, 7-9 weeks) were anaesthetised with an injection of pentobarbital $\left(60 \mathrm{mg} \mathrm{kg}^{-1}\right.$, i.p.) and positioned with a stereotaxic apparatus. A small piece of a razor blade $(2.5 \mathrm{~mm}$ wide $)$ was glued onto a rod that was clamped onto a micromanipulator. After removing a portion of the skull ( $3 \mathrm{~mm}$ wide and $4 \mathrm{~mm}$ long, including the bregma), the blade was inserted to a 
depth of $4.0 \mathrm{~mm}$ at the midline to transect the VHC. To avoid damaging the sagittal sinus, the blade was initially shifted $0.5 \mathrm{~mm}$ to the right and inserted $0.5 \mathrm{~mm}$ into the cerebral cortex, and was then returned to the midline position as the blade was lowered. After slowly removing the blade, the piece of skull was replaced, and the scalp was closed with sutures. Animals receiving this procedure were viable for more than 3 months.

Electrophysiology

Transverse hippocampal slices $(450 \mu \mathrm{m}$ thick $)$ were cut with a vibrating microtome (LinearSlicer PRO7, Dosaka EM, Kyoto, Japan) in ice-cold artificial cerebrospinal fluid (ACSF) (in $\mathrm{mM}: \mathrm{NaCl}, 119 ; \mathrm{KCl}, 2.5 ; \mathrm{CaCl}_{2}, 2.5 ; \mathrm{MgSO}_{4}, 1.3$; $\mathrm{NaH}_{2} \mathrm{PO}_{4}, 1.0 ; \mathrm{NaHCO}_{3}, 26$; glucose, 10 , saturated with $95 \% \mathrm{O}_{2} / 5 \% \mathrm{CO}_{2}$ ). Brains were fixed on an agar block, which was made by two pieces of agar (with a slope of $20^{\circ}$ ) stuck together at a right angle and mounted on the cutting stage. We lowered the left rear or right rear of the brain using the agar slopes when cutting the left or right hemisphere, respectively. Slices from a similar septotemporal level were used for the experiments. Recordings were made in a submerged slice chamber perfused with ACSF at $32 \pm 1{ }^{\circ} \mathrm{C}$. Electrodes filled with $0.9 \% \mathrm{NaCl}$ were used for extracellular recording. Synaptic responses were evoked at $0.1 \mathrm{~Hz}$ using a bipolar tungsten electrode. Synaptic plasticity-inducing stimuli were given at baseline stimulus strength. The field EPSP (fEPSP) slope was expressed as a percentage of the mean slope value before the stimulations. Synaptic currents were recorded from CA1 pyramidal neurones using the 
blind-patch technique (Blanton et al. 1989) in the whole-cell voltage-clamp mode (Axopatch 1D; Axon Instruments, Foster City, CA, USA). A high- $\mathrm{Mg}^{2+}$ and high-Ca ${ }^{2+}$ (4 $\mathrm{mM}$ of $\mathrm{MgSO}_{4}$ and $\mathrm{CaCl}_{2}$ ) ACSF was used to increase membrane stability in the presence of bicuculline. Patch electrodes (4-6 M $\Omega$ ) were filled with an intracellular solution (in mM: cesium gluconate, 122.5; CsCl, 17.5; Hepes buffer, 10; EGTA, 0.2; $\mathrm{NaCl}, 8 ; \mathrm{Mg}$-ATP, 2 ; $\mathrm{Na}_{3}-\mathrm{GTP}, 0.3 ; \mathrm{pH}$ 7.2). We recorded NMDA EPSCs at $+10 \mathrm{mV}$ in the presence of 6,7-dinitroquinoxaline-2,3-dione (DNQX, $20 \mu \mathrm{M})$ and bicuculline (30 $\mu \mathrm{M})$. We adopted a relatively low holding potential to obtain stable recordings of NMDA EPSCs throughout the experiment (Kawakami et al. 2003; Wu et al. 2005; Kawakami et al. 2008). The series resistance (10-30 M 2 ) was regularly monitored during recordings. Cells were rejected if more than a $15 \%$ change in series resistance occurred during the experiment. All records were filtered at $2 \mathrm{kHz}$, digitised at $4 \mathrm{kHz}$, and stored on a computer equipped with an analog-to-digital converter (PowerLab 2/25, ADInstruments, Bella Vista, Australia). No synaptic failure was detected in our experiments. All data were expressed as means \pm SEM and analysed with Student's t-test.

Lentivirus injection guided by in vivo electrophysiology

Under ketamine (200 $\left.\mathrm{mg} \mathrm{kg}^{-1}\right)$ and xylazine $\left(2.5 \mathrm{mg} \mathrm{kg}^{-1}\right)$ anaesthesia, nine-week-old mice were fixed in a stereotaxic apparatus. A small craniotomy (diameter $1.0 \mathrm{~mm}$ ) was made at the following stereotaxic coordinates: anterior-posterior $-2.0 \mathrm{~mm}$ and lateral $2.0 \mathrm{~mm}$ from bregma. The electrode was pulled from a thick-walled 
borosilicate glass pipette (P-1000, Sutter Instruments, Novato, CA, USA). The tip was broken such that the diameter of the electrodes was 10-20 $\mu \mathrm{m}$. Lentivirus suspended in Hepes-Hanks solution was filled from the tip. The electrode was attached to a water driven fine manipulator (MO-202U, Narishige, Tokyo, Japan) and inserted slowly into the brain. Extracellular neural activity was monitored through the electrode with an AC amplifier (MODEL 1800, A-M SYSTEMS, Carlsborg, WA, USA). CA3 multi-unit activity is characterised by local field gamma $(30-80 \mathrm{~Hz})$ oscillation patterns (Shinohara et al. 2008). After detecting these oscillations, lentivirus was slowly injected by microsyringe with a motor driven injector (BAS Bioanalytical Systems, Lafayette, IN, USA) connected to a glass pipette filled with mineral oils $(0.4 \mu \mathrm{l} / 10 \mathrm{~min})$. The scalp was disinfected and sutured after the injection.

Analysis of CA1 spine morphology in virus-injected mice

Mice were deeply anaesthetised with pentobarbital (60 mg kg-1, i.p.) and transcardially perfused with a fixative containing $4.0 \%$ PFA, $0.05 \%$ glutaraldehyde, and $1.0 \%$ picric acid in $0.1 \mathrm{M} \mathrm{PB} \mathrm{pH} 7.4$ for $12 \mathrm{~min}$. Brain sections were first incubated in $20 \%$ normal goat serum (NGS) diluted in TBS for $30 \mathrm{~min}$ and then incubated for 24 hours in an anti-green fluorescent protein (GFP) antibody (Fukata et al. 2001) diluted in TBS containing 3\% NGS. Subsequently, the sections were washed in TBS and incubated overnight in TBS with 1.0\% NGS and biotinylated goat anti-mouse antibody (diluted in 1:100; Vector Laboratories, Burlingame, CA, USA). After washes in TBS, the sections were incubated in ABC complex (Vector Laboratories) diluted in TBS and 
then washed in Tris buffer (TB) $\mathrm{pH} 7.4$. Peroxidase was visualised with DAB $(0.05 \%$ in TB) using $0.0001 \% \mathrm{H}_{2} \mathrm{O}_{2}$ as a substrate for $10 \mathrm{~min}$. The sections were treated with $1 \%$ OsO4 in $\mathrm{PB}$ for 40 min, washed in $\mathrm{PB}$ and distilled water, and then contrasted in uranyl acetate for $40 \mathrm{~min}$. They were dehydrated with an ethanol series, propylene oxide, and flat-embedded in epoxy resin (Durcupan ACM; Sigma-Aldrich, St. Louis, MO, USA). After polymerisation, corresponding small parts $\left(0.5 \times 0.5 \mathrm{~mm}^{2}\right)$ of the middle one third of stratum radiatum of the CA1 area in the left and right dorsal hippocampus (bregma $-1.94 \mathrm{~mm}$ ) were trimmed. Ultrathin sections were cut at $70 \mathrm{~nm}$ with an ultramicrotome (Reichert Ultracut UCT; Leica, Vienna, Austria) and analysed in JEM-1010 (JEOL, Tokyo, Japan). PSD areas were calculated by multiplying the total PSD length in the serial images by the section thickness $(70 \mathrm{~nm})$. Spine volumes were calculated after reconstruction of spine profiles with the Reconstruct software (http://synapses.clm.utexas.edu/tools/reconstruct/reconstruct.stm). Mushroom-type synapses were defined as spines that have perforated PSDs (Popov et al. 2004).

Results

$\beta 2 m$ proteins localise in hippocampal synapses

Synaptic localisation of MHCI proteins has been reported in the rat visual cortex (Needleman et al. 2010) and in mouse hippocampal neurones in culture (Goddard et al. 2007). In this study, we examined the subcellular localisation of $\beta 2 \mathrm{~m}$ proteins in the adult mouse hippocampus using subcellular fractionation and immunoblotting. As shown in Fig. 2, $\beta 2 \mathrm{~m}$ proteins were detected in the PSD-95 positive 
$\mathrm{P} 2$ fraction (P2) and synaptosome fraction (Syn) prepared from the WT hippocampus, but not in any fractions prepared from the $\beta 2 \mathrm{~m}$-deficient mouse hippocampus. Since $\beta 2 \mathrm{~m}$ proteins are associated noncovalently with the transmembrane heavy chain, they were solubilised from the synaptosome fraction with Triton X-100 treatment and detected in the soluble fraction (Sol, Fig. 2). These results indicate that $\beta 2 \mathrm{~m}$ proteins localise in mouse hippocampal synapses.

Inhibitory effects of Ro 25-6981 on NMDA EPSCS

We examined the effects of Ro 25-6981 on NMDA EPSCs using hippocampal slices prepared from $\beta 2 \mathrm{~m}$-deficient and WT mice. To measure NMDA EPSCs, whole-cell recordings were made from CA1 pyramidal neurones (Fig. 3) in the presence of 6,7-dinitroquinoxaline-2,3-dione (DNQX, $20 \mu \mathrm{M})$ and bicuculline $(30 \mu \mathrm{M})$ at a holding potential of $+10 \mathrm{mV}$ (Kawakami et al. 2003). To discriminate between excitatory synapses on the apical and basal dendrites of CA1 pyramidal neurones, NMDA EPSCs were independently elicited by electrical stimuli applied either at the stratum radiatum (Fig. $3 A$ ) or at the stratum oriens (Fig. $3 B$ ) of area CA1. Hippocampal CA1 pyramidal neurones receive major excitatory inputs from Sch fibres originating from ipsilateral CA3 pyramidal neurones and commissural (Com) fibres from contralateral CA3 pyramidal neurones. To characterise the NMDA receptors selectively in the Sch-CA1 pyramidal neurone synapses, we used hippocampal slices prepared from VHCT mice in which Com fibres had been denervated (Kawakami et al. 2003; Wu et al. 2005) (see Methods). We first examined NMDA EPSCs in hippocampal slices 
from $\beta 2 \mathrm{~m}$-deficient mice. In apical synapses, Ro 25-6981 (0.6 $\mu \mathrm{M})$ reduced peak amplitudes of NMDA EPSCs to a similar extent in the left and right hippocampal slices for both naïve and VHCT mice (Naïve: left, $51 \pm 2 \%$ of control, $\mathrm{n}=7$ from 7 animals; right, $52 \pm 2 \%$ of control, $\mathrm{n}=7$ from 7 animals; VHCT: left, $50 \pm 1 \%$ of control, $\mathrm{n}=7$ from 7 animals; right, $51 \pm 1 \%$ of control, $\mathrm{n}=7$ from 7 animals; $\mathrm{P}>0.05$ for all combinations; Fig. 3Ab). Likewise, Ro 25-6981 sensitivity of basal synapses was comparable between the left and right hippocampus for both naïve and VHCT mice (Naïve: left, $55 \pm 2 \%$ of control, $\mathrm{n}=7$ from 7 animals; right, $53 \pm 3 \%$ of control, $\mathrm{n}=7$ from 7 animals; VHCT: left, $52 \pm 1 \%$ of control, $\mathrm{n}=7$ from 7 animals; left, $54 \pm 1 \%$ of control, $\mathrm{n}=7$ from 7 animals; $\mathrm{P}>0.05$ for all combinations; Fig. $3 B b$ ).

We next examined the sensitivity of NMDA EPSCs to Ro 25-6981 in hippocampal slices from WT mice. In naïve WT mice, Ro 25-6981 reduced the peak amplitudes of NMDA EPSCs to a similar extent in the left and right hippocampal slices in both apical (Naïve: left, $63 \pm 1 \%$ of control, $n=3$ from 3 animals; right, $63 \pm 3 \%$ of control, $\mathrm{n}=3$ from 3 animals; $\mathrm{P}>0.05$; Fig. $3 A c$ ) and basal synapses (Naïve: left, $64 \pm$ $1 \%$ of control, $\mathrm{n}=3$ from 3 animals; right, $64 \pm 1 \%$ of control, $\mathrm{n}=3$ from 3 animals; $\mathrm{P}$ $>$ 0.05; Fig. 3Bc). By contrast, VHCT WT mice showed asymmetrical Ro 25-6981 sensitivity. In apical synapses, Ro 25-6981 more effectively reduced NMDA EPSCs in left hippocampal slices than in right hippocampal slices (VHCT: left, $45 \pm 2 \%$ of control, $\mathrm{n}=3$ from 3 animals; right, $87 \pm 2 \%$ of control, $\mathrm{n}=3$ from 3 animals; $\mathrm{P}<$ 0.05; Fig. 3Ac). Conversely, in basal synapses, slices from the right hippocampus exhibited greater sensitivity to Ro 25-6981 compared to the left (VHCT: left, $84 \pm 1 \%$ 
of control, $\mathrm{n}=3$ from 3 animals; right, $45 \pm 1 \%$ of control, $\mathrm{n}=3$ from 3 animals; $\mathrm{P}<$ 0.05; Fig. 3Bc). The results obtained in WT mice were consistent with our earlier report (Kawakami et al. 2003). In VHCT slices, Sch-CA1 synapses are responsible for NMDA EPSCs. Thus, our results indicate that the Sch-CA1 synapses of $\beta 2 \mathrm{~m}$-deficient mice lack asymmetries with regard to Ro 25-6981 sensitivity of NMDA EPSCs.

We found that Ro $25-6981$ sensitivity in naïve $\beta 2 \mathrm{~m}$-deficient mice, having both Sch fibre and Com fibre synapses, was comparable to that in VHCT $\beta 2 \mathrm{~m}$-deficient mice that have Sch fibre synapses only (Fig. $3 A b$ and $B b$ ). Thus in $\beta 2 \mathrm{~m}$-deficient mice, the sensitivity of Com fibre synapses to Ro 25-6981 is expected to be similar to that of Sch fibre synapses. Because it is not possible to selectively stimulate Com fibres in area CA1, we examined the sensitivity of NMDA EPSCs to Ro 25-6981 in Com fibre synapses formed on the basal dendrites of CA3 pyramidal neurones by stimulating the ventral fimbria in hippocampal slices from naïve mice (Kawakami et al. 2003). To reduce contamination of Com fibre responses on the apical dendrites of CA3 pyramidal neurones and to avoid antidromic activation of ipsilateral CA3 axons by stimulation at the ventral fimbria, we optimised the cutting angles for preparation of hippocampal slices (Kawakami et al. 2003) (see Methods). In hippocampal slices prepared with our procedure, we confirmed that electrical stimulation at the ventral fimbria rarely induced fEPSPs and antidromic population spikes in the stratum radiatum and stratum pyramidale of area CA3, respectively. We did not use slices that exhibited EPSCs with multiple peaks after stimulation at the ventral fimbria. Consistent with our previous results obtained using the WT hippocampus (Kawakami et al. 2003), Ro 25-6981 
reduced NMDA EPSCs in the left Com-CA3 synapses more intensely than it did in the right (left, $48 \pm 2 \%$ of control, $\mathrm{n}=7$ from 7 animals; right, $83 \pm 1 \%$ of control, $\mathrm{n}=7$ from 7 animals; $\mathrm{P}<0.05$; Fig. 4, WT). In $\beta 2 \mathrm{~m}$-deficient mice, however, Ro 25-6981 reduced the peak amplitude of NMDA EPSCs at Com-CA3 synapses to a similar extent in the left and right hippocampal slices (left, $49 \pm 3 \%$ of control, $n=7$ from 7 animals; right, $49 \pm 2 \%$ of control, $\mathrm{n}=7$ from 7 animals; $\mathrm{P}>0.05$; Fig. $4, \beta 2 \mathrm{~m} \mathrm{KO}$ ), and the levels of inhibition were comparable to those of Sch-CA1 synapses (Fig. $3 A b$ and $B b$, VHCT). These results, obtained using naïve mice, support our prediction that Ro 25-6981 sensitivity of NMDA EPSCs in the $\beta 2 \mathrm{~m}$-deficient hippocampus is similar between Sch and Com fibre synapses, and suggest that the lack of asymmetry in the $\beta 2 \mathrm{~m}$-deficient hippocampus is not caused by VHCT. Together these observations suggest that the hippocampal circuitry of $\beta 2 \mathrm{~m}$-deficient mice lacks both $\mathrm{L}-\mathrm{R}$ and apical-basal asymmetries with respect to Ro 25-6981 sensitivity of NMDA EPSCs.

Morphology of dendritic spines and synapses in the $\beta 2 m$-deficient mouse hippocampus

We then examined the morphological characteristics of Sch-CA1 synapses in the $\beta 2 \mathrm{~m}$-deficient hippocampus. Naïve $\beta 2 \mathrm{~m}$-deficient mice (9 weeks old) were stereotactically injected with vesicular stomatitis virus glycoprotein-G-coated lentivirus expressing GFP into either the left or right CA3 region (Shinohara et al. 2008). This led to selective labelling of CA3 pyramidal neurones and their axon terminals in CA1 with GFP in the ipsilateral side of the injection (Grinevich et al. 2005). Using electron microscopy, we examined CA1 dendritic spines making synaptic contact with 
GFP-labelled axon terminals in the middle one-third of the stratum radiatum in serial ultrathin sections (Fig. 5A). No significant difference in PSD area size, spine head volume, or the ratio of mushroom-type spines was detected between the left and right hippocampus (PSD area size: left, $0.0421 \pm 0.0023 \mu \mathrm{m}^{2}, \mathrm{n}=95$ from 3 animals; right, $0.0457 \pm 0.0028 \mu \mathrm{m}^{2}, \mathrm{n}=95$ from 3 animals, $\mathrm{P}>0.05$, Fig. $5 B$; spine head volume: left, $0.0229 \pm 0.0024 \mu \mathrm{m}^{3}, \mathrm{n}=95$ from 3 animals; right, $0.0228 \pm 0.0022 \mu \mathrm{m}^{3}, \mathrm{n}=95$ from 3 animals, $\mathrm{P}>0.05$, Fig. $5 C$; mushroom-type ratio: left, $20.0 \pm 1.0 \%, \mathrm{n}=3$; right, $20.0 \pm$ $1.7 \%, \mathrm{n}=3, \mathrm{P}>0.05$, Fig. $5 D$ ). The ultrastructural parameter values of the $\beta 2 \mathrm{~m}$-deficient hippocampal synapses were very similar to those of the ' $\varepsilon 2$-dominant' synapses that we had previously reported in the WT hippocampus (Shinohara et al. 2008).

To further characterise hippocampal synapses in $\beta 2 \mathrm{~m}$-deficient mice, we examined the dose-response characteristics of Ro 25-6981 inhibition of NMDA EPSCs and the stimulation-frequency dependency of synaptic plasticity in $\beta 2 \mathrm{~m}$-deficient synapses and compared them with those in ' $\varepsilon 2$-dominant' and ' $\varepsilon 2$-nondominant' synapses in the iv mouse hippocampus. In these following experiments, we used hippocampal slices prepared from naïve $\beta 2 \mathrm{~m}$-deficient mice and naïve $i v$ mice. Because Ro 25-6981 sensitivity of $\beta 2 \mathrm{~m}$-deficient synapses was comparable between naïve and VHCT mice (Fig. 3), we carried out the following experiments using hippocampal slices from naïve $\beta 2 \mathrm{~m}$-deficient mice. Since ' $\varepsilon 2$-dominant' and ' $\varepsilon 2$-nondominant' 
synapses are formed on the basal and apical dendrites of CA1 pyramidal neurones, respectively (Fig. 1, iv), the properties of these two populations of synapses can be analysed selectively in naïve $i v$ mice (Kawakami et al. 2008).

Comparison of Ro 25-6981 sensitivity of NMDA EPSCs between $\beta 2 m$-deficient mice and iv mice

To evaluate the extent of Ro 25-6981 sensitivity of $\beta 2 \mathrm{~m}$-deficient hippocampal synapses, we compared the dose-response characteristics of Ro 25-6981 inhibition of NMDA EPSCs between $\beta 2 \mathrm{~m}$-deficient mice and $i v$ mice. To record NMDA EPSCs at basal and apical synapses of CA1 pyramidal neurones in hippocampal slices from naïve $i v$ mice, electrical stimuli were applied either at the stratum oriens or at the stratum radiatum of area CA1, respectively (Fig. 6). In hippocampal slices from naïve $\beta 2 \mathrm{~m}$-deficient mice, NMDA EPSCs were elicited in apical synapses of CA1 pyramidal neurones in response to electrical stimuli applied at the stratum radiatum of area CA1. As shown in Fig. 6, the dose-response relationship obtained in basal synapses of the $i v$ hippocampus was shifted toward the left when compared to that in apical synapses of the $i v$ hippocampus, and was almost the same as that obtained in hippocampal synapses of $\beta 2 \mathrm{~m}$-deficient mice. This indicates that the extent of Ro 25-6981 sensitivity of $\beta 2 \mathrm{~m}$-deficient hippocampal synapses is similar to that of ' $\varepsilon 2$-dominant' synapse in the $i v$ mouse hippocampus.

Relationship between stimulation frequency and synaptic plasticity 
Because synaptic plasticity in the hippocampus is known to be dependent on stimulation frequency (Dudek \& Bear, 1992; Migaud et al. 1998; Philpot et al. 2007), we next compared the stimulation-frequency dependency of synaptic plasticity between $\beta 2 \mathrm{~m}$-deficient mice and $i v$ mice. We measured fEPSPs using hippocampal slices perfused with ACSF. To measure fEPSPs at basal and apical synapses of CA1 pyramidal neurones in hippocampal slices from naïve $i v$ mice, extracellular recording and stimulating electrodes were placed in either the stratum oriens or the stratum radiatum of area CA1, respectively (Fig. $7 A$ ) (Kawakami et al. 2008). In hippocampal slices prepared from naïve $\beta 2 \mathrm{~m}$-deficient mice, recording and stimulating electrodes were placed in the stratum radiatum of area CA1, and fEPSPs evoked on the apical dendrites of CA1 pyramidal neurones were measured (Fig. 7A). The baseline stimulus intensity was adjusted so that it induced fEPSPs with amplitude of about one-third of the maximum response. Synaptic plasticity-inducing stimuli were given at baseline stimulus strength. In hippocampal slices prepared from adult $i v$ mice, tetanic stimulation $(100 \mathrm{~Hz}$ for $1 \mathrm{sec})$ induced long-term potentiation (LTP) in the slope of the fEPSP in both basal and apical synapses of CA1 pyramidal neurons, respectively (relative fEPSP slopes 40 min after tetanic stimulation: basal synapses: $172 \pm 6 \%$ of control, $n=11$ from 9 animals; apical synapses: $172 \pm 6 \%$ of control, $\mathrm{n}=16$ from 14 animals; Fig. $7 B$ and $D$ ). Similarly, hippocampal slices from adult $\beta 2 \mathrm{~m}$-deficient mice showed LTP in response to the same tetanus (relative fEPSP slopes $40 \mathrm{~min}$ after tetanic stimulation: $166 \pm 3 \%$ of control, $\mathrm{n}=11$ from 10 animals, Fig. $7 B$ and $D$ ). No significant difference $(\mathrm{P}>0.05)$ was observed in the amplitude of LTP between these three populations of 
synapses. Intermediate frequency stimulation ( $10 \mathrm{~Hz}$ for $2 \mathrm{sec}, 6$ times, $10 \mathrm{sec}$ apart) resulted in a moderate increase in the fEPSP slopes in all three populations of synapses (basal synapses in $i v$ mice: $124 \pm 5 \%$ of control, $\mathrm{n}=13$ from 9 animals; apical synapses in $i v$ mice: $113 \pm 3 \%$ of control, $\mathrm{n}=12$ from 7 animals; $\beta 2 \mathrm{~m}$-deficient synapses: $130 \pm$ $6 \%$ of control, $\mathrm{n}=11$ from 11 animals, Fig. $7 D$ ). Although the potentiation observed in apical synapses in $i v$ mice was slightly lower than the potentiation observed in the other two populations of synapses, there was no significant difference $(P>0.05)$ in the extent of potentiation between three populations of synapses (Fig. $7 D$ ). The delivery of low frequency stimulation ( $1 \mathrm{~Hz}$ for $15 \mathrm{~min}$ ) induced no detectable change in the fEPSP slopes in both basal synapses in $i v$ mice ( $100 \pm 4 \%$ of control, $\mathrm{n}=13$ from 12 animals) and $\beta 2 \mathrm{~m}$-deficient synapses (105 $\pm 6 \%$ of control, $\mathrm{n}=11$ from 10 animals), whereas significant long-term depression (LTD) was detected in apical synapses in $i v$ mice $(79 \pm$ $3 \%$ of control, $\mathrm{n}=14$ from 12 animals, $\mathrm{P}<0.01$ ) (Fig. $7 C$ and $D$ ). No significant difference $(\mathrm{P}>0.05)$ was observed between basal synapses in iv mice and $\beta 2 \mathrm{~m}$-deficient synapses (Fig. $7 C$ and $D$ ). We also examined the basal synapses of $\beta 2 \mathrm{~m}$-deficient mice using the same low frequency stimulation protocol, and LTD was not observed (101 $\pm 1 \%$ of control, $\mathrm{n}=8$ from 5 animals, data not shown). These results indicate that the relationship between stimulation frequency and synaptic plasticity of $\beta 2 \mathrm{~m}$-deficient synapse is very similar to that of the ' $\varepsilon 2$-dominant' synapse in $i v$ mice. 


\section{Discussion}

To directly test our hypothesis that MHCI is critical for the generation of asymmetries in hippocampal circuitry, we analysed $\beta 2 \mathrm{~m}$-deficient mice that lack cell surface expression of MHCI. We found that the $\beta 2 \mathrm{~m}$-deficient hippocampus lacked both L-R and apical-basal asymmetries in neuronal circuitry. Our results indicated that Ro 25-6981 sensitivity of NMDA EPSCs at $\beta 2 \mathrm{~m}$-deficient synapses was comparable between the left and right hippocampus and between the apical and basal synapses of pyramidal neurones for both Sch and Com fibre synapses (Fig. 3 and 4). We also observed a lack of $\mathrm{L}-\mathrm{R}$ and apical-basal asymmetries in the morphological characteristics of dendritic spines (Fig. 5) and in the stimulation-frequency dependency of synaptic plasticity (Fig. 7 and see text), respectively. Dose-response characteristics of Ro 25-6981 inhibition and stimulation-frequency dependency of synaptic plasticity of $\beta 2 \mathrm{~m}$-deficient synapses were very similar to those of the ' $\varepsilon 2$-dominant' synapse in $i v$ mice (Fig. 6 and 7). Furthermore, the morphological characteristics evaluated by PSD area size, spine head volume, and ratio of mushroom-type spines of $\beta 2 \mathrm{~m}$-deficient synapses were also comparable to those of the ' $\varepsilon 2$-dominant' synapse in WT mice (Fig. 5). As shown in Fig. 8 , the $\beta 2 \mathrm{~m}$-deficient mouse hippocampus lacks ' $\varepsilon 2$-nondominant' synapses and thus contains ' $\varepsilon 2$-dominant' synapses only, which results in a total loss of circuit asymmetry. These observations support the hypothesis that MHCI function is crucial for generating asymmetries in hippocampal circuitry.

We have previously shown that ' $\varepsilon 2$-dominant' and ' $\varepsilon 2$-nondominant' synapses differ in early postnatal development of synaptic plasticity; that is, LTP of the 
' $\varepsilon 2$-dominant' synapses develops earlier than LTP of the ' $\varepsilon 2$-nondominant' synapses (Kawakami et al. 2003; Kawakami et al. 2008). It was not known, however, whether these two populations of synapses differ in their functional properties as animals matured. In the present study, we have shown that ' $\varepsilon 2$-nondominant' synapses generate significant LTD in response to low frequency stimulation in hippocampal slices prepared from adult $i v$ mice (Fig. 7); however, this does not occur with ' $\varepsilon 2$-dominant' synapses. These results provide direct evidence that the ' $\varepsilon 2$-dominant' and ' $\varepsilon 2$-nondominant' synapses in the adult mouse hippocampus differ in their abilities to express synaptic plasticity. The loss of low-frequency-stimulation-induced LTD has previously been reported in $\beta 2 \mathrm{~m}$ and TAP double-deficient mice (Huh et al. 2000). In the present study, we also observed the loss of LTD in the $\beta 2 \mathrm{~m}$-deficient hippocampus, in which every CA3-CA1 synapse was an ' $\varepsilon 2$-dominant' synapse with a high sensitivity to Ro 25-6981. Thus, our results indicate that the loss of LTD is a characteristic of 'E2-dominant' synapses, which is consistent with recent evidence suggesting that synapses with a high $\varepsilon 2 / \varepsilon 1$ subunit ratio favor LTP induction (Barria \& Malinow, 2005; Yashiro \& Philpot, 2008).

A recent study reported that NMDA EPSCs at hippocampal synapses in $\beta 2 \mathrm{~m}$ and TAP double-deficient mice showed a similar sensitivity to Ifenprodil, another $\varepsilon 2$ subunit-selective antagonist, with those in WT mice (Fourgeaud et al. 2010). In that study, the authors used hippocampal slices prepared from naïve mice. Since naïve WT slices contain Sch and Com fibres and they make both ' $E 2$-dominant' and ' $\varepsilon 2$-nondominant' synapses, NMDA EPSCs will show an intermediate sensitivity to an 
ع2 subunit-selective antagonist (Fig. 3, WT, Naïve); furthermore, Ifenprodil is known to be less potent and less selective than Ro 25-6981 (Fischer et al. 1997). Under these conditions, it is plausible that a small difference in antagonist sensitivity between naïve WT and mutant mice may not be detected.

Our results provide a first step in elucidating the cellular process that generates hippocampal asymmetry; however, there remain unanswered questions on the role of MHCI molecules in the process. First, it is unclear whether our results reflect a specific effect of MHCI on the generation of circuit asymmetries or a consequence of generalised failure of synapse maturation caused by MHCI deficiency. For example, the expression of NMDAR $\varepsilon 1$ subunits in the mouse hippocampus in the early postnatal stage is absent or very low, whereas the $\varepsilon 2$ subunit is already expressed at high levels (Watanabe et al. 1992; Monyer et al. 1994; Ito et al. 1996). Therefore, at this stage of development, Ro 25-6981 sensitivity of NMDA EPSCs will be identical in every hippocampal CA3-CA1 synapse. Hippocampal asymmetry is thus considered to be a property acquired during synapse development. Reports have indicated that MHCI proteins play a key role in synapse maturation such as activity-dependent rearrangement of neuronal connections in developing nervous systems (Huh et al. 2000; Goddard et al. 2007; Datwani et al. 2009; Glynn et al. 2011). Thus, if MHCI deficiency impairs synapse maturation in the developing hippocampus, then it might affect the generation of hippocampal asymmetry as well. Therefore, we cannot rule out the possibility that our results reflect a generalised defect of synapse maturation caused by MHCI deficiency. Second, recent studies have suggested that MHCI heavy chains not 
associated with $\beta 2 \mathrm{~m}$ and/or peptide (referred to as open conformers) also play a role in neurodevelopment (Glynn et al. 2011; Bilousova et al. 2012). This raises the possibility that our findings obtained using $\beta 2 \mathrm{~m}$-deficient mice might result from an increased amount of MHCI open conformers rather than 'MHCI loss-of-function'. To address this issue, experiments using knockout mice, which lack expression of specific MHCI heavy chains, are required. Third, it has been reported that MHCI plays an important role in neuronal injury responses in both the peripheral and central nervous systems (Oliveira et al. 2004; Boulanger, 2009). Thus, some of our results obtained using VHCT $\beta 2 \mathrm{~m}$-deficient mice might be influenced by an altered nerve injury response in $\beta 2 \mathrm{~m}$-deficient mice.

Synapse formation in the mammalian CNS is thought to involve specific target cell recognition processes between presynaptic and postsynaptic neurones (Goodman \& Shatz, 1993). To establish asymmetrical circuitry in the hippocampus, pyramidal neurones are further required to distinguish between axons from the left and those from the right hippocampal neurones, and between the apical and basal dendritic spines of individual neurones. An accurate molecular discrimination capacity of MHCI molecules will allow pyramidal neurones to accomplish these complicated discrimination processes. Although further studies will be necessary to elucidate the details of MHCI function in hippocampal asymmetry, our present results suggest a novel role for MHCI molecules in the generation of defined neuronal circuits in the brain. 
References

Aizawa H, Bianco IH, Hamaoka T, Miyashita T, Uemura O, Concha ML, Russell C, Wilson SW \& Okamoto H (2005). Laterotopic representation of left-right information onto the dorso-ventral axis of a zebrafish midbrain target nucleus. Current Biology 15, $238-243$

Aizawa H, Goto M, Sato T \& Okamoto H (2007). Temporally regulated asymmetric neurogenesis causes left-right difference in the zebrafish habenular structures.

Developmental Cell 12, 87-98.

Barria A \& Malinow R (2005). NMDA receptor subunit composition controls synaptic plasticity by regulating binding to CaMKII. Neuron 48, 289-301.

Bijlmakers M \& Ploegh H (1993). Putting together an MHC class I molecule. Curr Opin Immunol 5, 21-26.

Bilousova T, Dang H, Xu W, Gustafson S, Jin Y, Wickramasinghe L, Won T, Bobarnac G, Middleton B, Tian J \& Kaufman DL (2012). Major histocompatibility complex class I molecules modulate embryonic neuritogenesis and neuronal polarization. $J$ Neuroimmunol 247, 1-8.

Blanton MG, Loturco JJ \& Kriegstein AR (1989). Whole cell recording from neurons in slices of reptilian and mammalian cerebral cortex. $J$ Neurosci Methods 30, 203-210.

Boulanger LM (2009). Immune proteins in brain development and synaptic plasticity. Neuron 64, 93-109.

Boulanger L \& Shatz C (2004). Immune signalling in neural development, synaptic plasticity and disease. Nature Reviews Neuroscience 5, 521-531. 
Carlin R, Grab D, Cohen R \& Siekevitz P (1980). Isolation and characterization of postsynaptic densities from various brain regions: enrichment of different types of postsynaptic densities. J Cell Biol 86, 831-843.

Chizh B, Headley P \& Tzschentke T (2001). NMDA receptor antagonists as analgesics: focus on the NR2B subtype. Trends Pharmacol Sci 22, 636-642.

Concha ML, Bianco IH \& Wilson SW (2012). Encoding asymmetry within neural circuits. Nature Reviews Neuroscience 13, 832-843.

Corriveau R, Huh G \& Shatz C (1998). Regulation of class I MHC gene expression in the developing and mature CNS by neural activity. Neuron 21, 505-520.

Datwani A, McConnell MJ, Kanold PO, Micheva KD, Busse B, Shamloo M, Smith SJ \& Shatz CJ (2009). Classical MHCI molecules regulate retinogeniculate refinement and limit ocular dominance plasticity. Neuron 64, 463-470.

Dudek S \& Bear M (1992). Homosynaptic long-term depression in area CA1 of hippocampus and effects of $N$-methyl-D-aspartate receptor blockade. Proc Natl Acad Sci U S A 89, 4363-4367.

Dulac C \& Torello A (2003). Molecular detection of pheromone signals in mammals: from genes to behaviour. Nature Reviews Neuroscience 4, 551-562.

Fischer G, Mutel V, Trube G, Malherbe P, Kew J, Mohacsi E, Heitz M \& Kemp J (1997). Ro 25-6981, a highly potent and selective blocker of $N$-methyl-D-aspartate receptors containing the NR2B subunit. Characterization in vitro. J Pharmacol Exp Ther 283, 1285-1292.

Fischer-Lindahl K (1997). On naming H2 haplotypes: functional significance of MHC class Ib alleles. Immunogenetics 46, 53-62. 
Fourgeaud L \& Boulanger LM (2010). Role of immune molecules in the establishment and plasticity of glutamatergic synapses. Eur J Neurosci 32, 207-217.

Fourgeaud L, Davenport CM, Tyler CM, Cheng TT, Spencer MB \& Boulanger LM (2010). MHC class I modulates NMDA receptor function and AMPA receptor trafficking. Proc Natl Acad Sci U S A 107, 22278-22283.

Fukata M, Nakagawa M, Itoh N, Kawajiri A, Yamaga M, Kuroda S \& Kaibuchi K (2001). Involvement of IQGAP1, an effector of Rac1 and Cdc42 GTPases, in cell-cell dissociation during cell scattering. Mol Cell Biol 21, 2165-2183.

Geschwind, N \& Galaburda, A (1987). Carebral Lateralization. MIT Press, CabmbridgeMA.

Glynn MW, Elmer BM, Garay PA, Liu X, Needleman LA, El-Sabeawy F \& McAllister AK (2011). MHCI negatively regulates synapse density during the establishment of cortical connections. Nat Neurosci 14, 442-U71.

Goddard CA, Butts DA \& Shatz CJ (2007). Regulation of CNS synapses by neuronal MHC class I. Proc Natl Acad Sci U S A 104, 6828-6833.

Goodman C \& Shatz C (1993). Developmental mechanisms that generate precise patterns of neuronal connectivity. Cell 72, 77-98.

Goto K, Kurashima R, Gokan H, Inoue N, Ito I \& Watanabe S (2010). Left-right asymmetry defect in the hippocampal circuitry impairs spatial learning and working memory in iv mice. Plos One 5, e15468.

Grinevich V, Brecht M \& Osten P (2005). Monosynaptic pathway from rat vibrissa motor cortex to facial motor neurons revealed by lentivirus-based axonal tracing. Journal of Neuroscience 25, 8250-8258.

Huh G, Boulanger L, Du H, Riquelme P, Brotz T \& Shatz C (2000). Functional 
requirement for class I MHC in CNS development and plasticity. Science 290, 2155-2159.

Hummel KP \& Chapman DB (1959). Visceral inversion and associated anomalies in the mouse. J Hered 50, 9-13.

Ishii T \& Mombaerts P (2008). Expression of nonclassical class I major histocompatibility genes defines a tripartite organization of the mouse vomeronasal system. Journal of Neuroscience 28, 2332-2341.

Ito I, Sakimura K, Mishina M \& Sugiyama H (1996). Age-dependent reduction of hippocampal LTP in mice lacking $N$-methyl-D-aspartate receptor $\varepsilon 1$ subunit. Neurosci Lett 203, 69-71.

Kawakami R, Shinohara Y, Kato Y, Sugiyama H, Shigemoto R \& Ito I (2003). Asymmetrical allocation of NMDA receptor $\varepsilon 2$ subunits in hippocampal circuitry. Science 300, 990-994.

Kawakami R, Dobi A, Shigemoto R \& Ito I (2008). Right isomerism of the brain in inversus viscerum mutant mice. Plos One 3, e1945.

Kohl MM, Shipton OA, Deacon RM, Rawlins JNP, Deisseroth K \& Paulsen O (2011). Hemisphere-specific optogenetic stimulation reveals left-right asymmetry of hippocampal plasticity. Nat Neurosci 14, 1617-1617.

Linda H, Hammarberg H, Piehl F, Khademi M \& Olsson T (1999). Expression of MHC class I heavy chain and beta 2-microglobulin in rat brainstem motoneurons and nigral dopaminergic neurons. J Neuroimmunol 101, 76-86.

Loconto J, Papes F, Chang E, Stowers L, Jones E, Takada T, Kumanovics A, Lindahl K \& Dulac C (2003). Functional expression of murine V213 pheromone receptors involves selective association with the M10 and M1 families of MHC class $\mathrm{Ib}$ molecules. Cell 112, 607-618. 
McConnell MJ, Huang YH, Datwani A \& Shatz CJ (2009). H2-K $\mathrm{K}^{\mathrm{b}}$ and H2-D ${ }^{\mathrm{b}}$ regulate cerebellar long-term depression and limit motor learning. Proc Natl Acad Sci U S A 106, 6784-6789.

Migaud M, Charlesworth P, Dempster M, Webster L, Watabe A, Makhinson M, He Y, Ramsay M, Morris R, Morrison J, O'Dell T \& Grant S (1998). Enhanced long-term potentiation and impaired learning in mice with mutant postsynaptic density-95 protein. Nature 396, 433-439.

Monyer H, Burnashev N, Laurie D, Sakmann B \& Seeburg P (1994). Developmental and regional expression in the rat brain and functional properties of four NMDA receptors. Neuron 12, 529-540.

Mutel V, Buchy D, Klingelschmidt A, Messer J, Bleuel Z, Kemp JA \& Richards JG (1998). In vitro binding properties in rat brain of $\left[{ }^{3} \mathrm{H}\right] \mathrm{Ro} 25-6981$, a potent and selective antagonist of NMDA receptors containing NR2B subunits. $J$ Neurochem 70, 2147-2155.

Needleman LA, Liu X, El-Sabeawy F, Jones EG \& McAllister AK (2010). MHC class I molecules are present both pre- and postsynaptically in the visual cortex during postnatal development and in adulthood. Proc Natl Acad Sci U S A 107, 16999-17004.

Neefjes J \& Momburg F (1993). Cell biology of antigen presentation. Curr Opin Immunol 5, 27-34.

Nonaka S, Shiratori H, Saijoh Y \& Hamada H (2002). Determination of left-right patterning of the mouse embryo by artificial nodal flow. Nature 418, 96-99.

Okada Y, Nonaka S, Tanaka Y, Saijoh Y, Hamada H \& Hirokawa N (1999). Abnormal nodal flow precedes situs inversus in iv and inv mice. Mol Cell 4, 459-468.

Oliveira A, Thams S, Lidman O, Piehl F, Hokfelt T, Karre K, Linda H \& Cullheim S (2004). A role for MHC class I molecules in synaptic plasticity and regeneration of 
neurons after axotomy. Proc Natl Acad Sci U S A 101, 17843-17848.

Philpot BD, Cho KKA \& Bear MF (2007). Obligatory role of NR2A for metaplasticity in visual cortex. Neuron 53, 495-502.

Popov V, Davies H, Rogachevsky V, Patrushev I, Errington M, Gabbot P, Bliss T \& Stewart M (2004). Remodelling of synaptic morphology but unchanged synaptic density during late phase long-term potentiation (LTP): A serial section electron micrograph study in the dentate gyrus in the anaesthetised rat. Neuroscience 128, 251-262.

Ribic A, Zhang M, Schlumbohm C, Maetz-Rensing K, Uchanska-Ziegler B, Fluegge G, Zhang W, Walter L \& Fuchs E (2010). Neuronal MHC class I molecules are involved in excitatory synaptic transmission at the hippocampal mossy fiber synapses of marmoset monkeys. Cell Mol Neurobiol 30, 827-839.

Shatz CJ (2009). MHC Class I: An unexpected role in neuronal plasticity. Neuron 64 , 40-45.

Shinohara Y, Hirase H, Watanabe M, Itakura M, Takahashi M \& Shigemoto R (2008). Left-right asymmetry of the hippocampal synapses with differential subunit allocation of glutamate receptors. Proc Natl Acad Sci U S A 105, 19498-19503.

Spiliotis E, Pentcheva T \& Edidin M (2002). Probing for membrane domains in the endoplasmic reticulum: Retention and degradation of unassembled MHC class I molecules. Mol Biol Cell 13, 1566-1581.

Supp DM, Brueckner M, Kuehn MR, Witte DP, Lowe LA, McGrath J, Corrales J \& Potter SS (1999). Targeted deletion of the ATP binding domain of left-right dynein confirms its role in specifying development of left-right asymmetries. Development 126, 5495-5504.

Supp DM, Witte DP, Potter SS \& Brueckner M (1997). Mutation of an axonemal 
dynein affects left right asymmetry in inversus viscerum mice. Nature 389, 963-966.

Vallortigara G (2000). Comparative neuropsychology of the dual brain: A stroll through animals' left and right perceptual worlds. Brain Lang 73, 189-219.

Vankaer L, Ashtonrickardt P, Ploegh H \& Tonegawa S (1992). TAPl mutant mice are deficient in antigen presentation, surface class I molecules, and $\mathrm{CD}^{-} 8^{+} \mathrm{T}$ cells. Cell 71, $1205-1214$

Watanabe M, Inoue Y, Sakimura K \& Mishina M (1992). Developmental changes in distribution of NMDA receptor channel subunit mRNAs. Neuroreport 3, 1138-1140.

Williams D, Barber B, Flavell R \& Allen H (1989). Role of beta-2-microglobulin in the intracellular-transport and surface expression of murine class-I histocompatibility molecules. Journal of Immunology 142, 2796-2806.

Wu Y, Kawakami R, Shinohara Y, Fukaya M, Sakimura K, Mishina M, Watanabe M, Ito I \& Shigemoto R (2005). Target-cell-specific left-right asymmetry of NMDA receptor content in Schaffer collateral synapses in $\varepsilon 1 / \mathrm{NR} 2 \mathrm{~A}$ knock-out mice. Journal of Neuroscience 25, 9213-9226.

Yashiro K \& Philpot BD (2008). Regulation of NMDA receptor subunit expression and its implications for LTD, LTP, and metaplasticity. Neuropharmacology 55, 1081-1094.

Zijlstra M, Bix M, Simister N, Loring J, Raulet D \& Jaenisch R (1990).

$\beta 2-$ Microglobulin deficient mice lack $\mathrm{CD}^{-} 8^{+}$cytolytic T cells. Nature $\mathbf{3 4 4}, \mathbf{7 4 2 - 7 4 6 .}$ 


\section{Author contributions}

Electrophysiology experiments were performed and analysed in the Ito lab by A.K., S.K., N.S., K.N., T.K., T.Y., R.S., Y.I., and I.I. Biochemical experiments were performed in the Fukata lab by Y.F., A.K., and M.F. Morphological experiments were performed in the Shigemoto lab by J.M.H., R.L., and R.S. The manuscript was written by A.K. and I.I. All authors have approved the final version of the manuscript.

\section{Acknowledgements}

The authors thank Prof. H. Hamada for the iv mice, and Dr. R. Kawakami and Dr. Y. Fukazawa for excellent technical support. This work was supported by the Ministry of Education, Culture, Sports, Science and Technology of Japan (Grant No. 21300125 and 221S0003 to I.I.), Research Fellow of the Japan Society for the Promotion of Science (Grant No. 21-2516 to A.K.), the Cooperative Study Program of National Institute for Physiological Sciences, and grants from the Spanish Ministry of Education and Science (BFU-2009-08404 to R.L). 
Figures and legends

WT

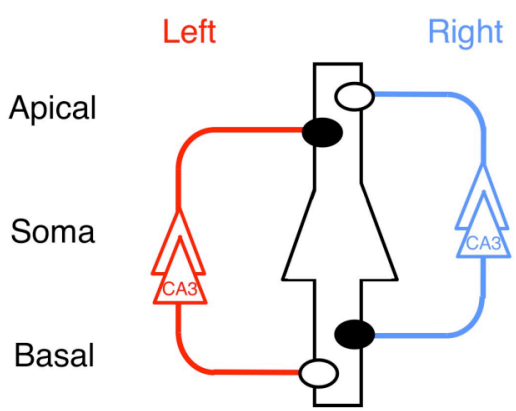

iv

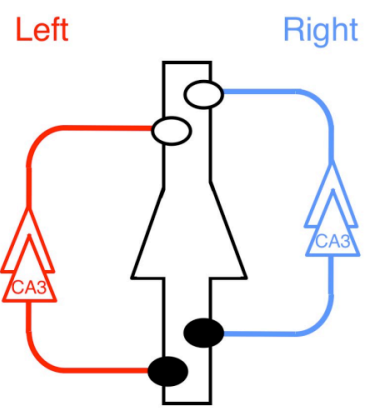

Figure 1. Hippocampal asymmetry and right isomerism of the $i v$ mouse hippocampus.

Left and right CA3 pyramidal neurones and their axons are coloured red and blue, respectively. A postsynaptic CA1 pyramidal neurone is in the centre, outlined in black, and it represents postsynaptic neurones in both left and right hemispheres. Closed and open circles represent ' $\varepsilon 2$-dominant' and ' $\varepsilon 2$-nondominant' synapses, respectively. Apical, apical dendrites; Basal, basal dendrites. 


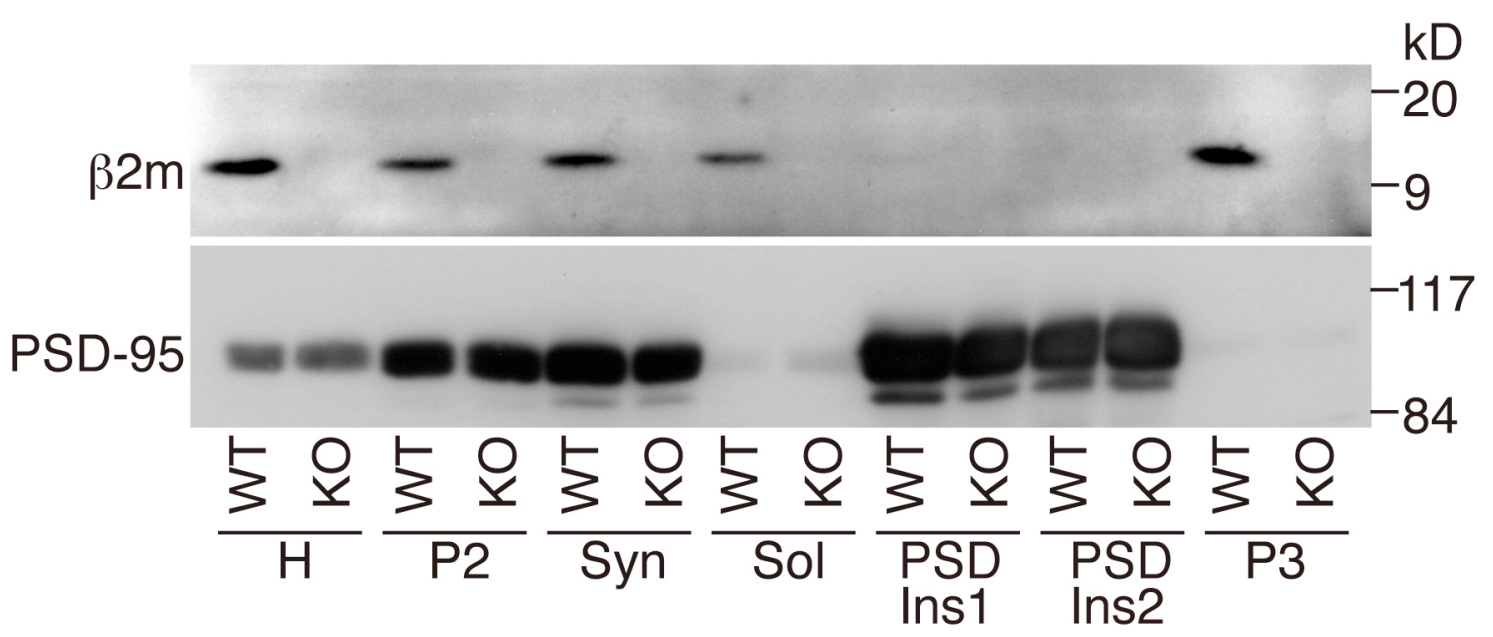

Figure 2. Subcellular distribution of $\beta 2 \mathrm{~m}$ proteins.

In preparations from the adult WT hippocampus (WT), $\beta 2 \mathrm{~m}$ proteins were detected in the PSD-95 positive P2 fraction (P2) and synaptosome fraction (Syn). In contrast, the $\beta 2 \mathrm{~m}$ protein was not detected in any fractions prepared from the $\beta 2 \mathrm{~m}$-deficient hippocampus (KO). H, homogenate; P, precipitate; Sol, Triton X-100-soluble; Ins, Triton X-100-insoluble postsynaptic density fractions. 
$A a$

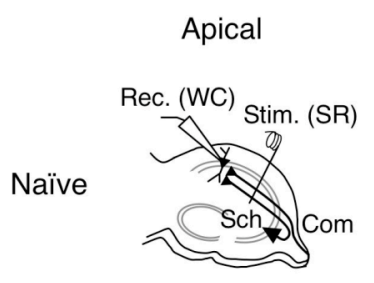

VHCT

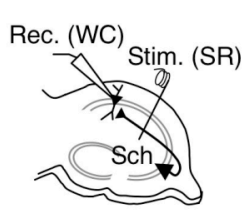

$B a$

Basal

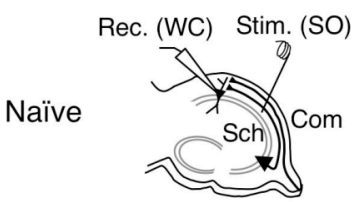

Rec. (WC) Stim. (SO)

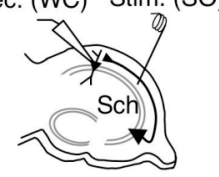

$b$
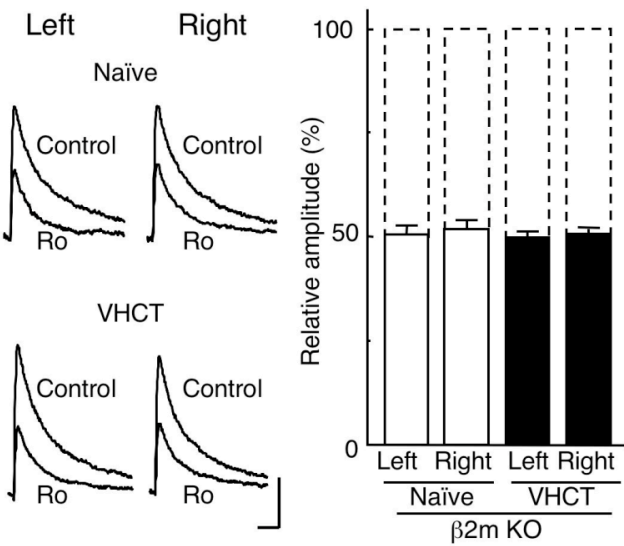

$b$
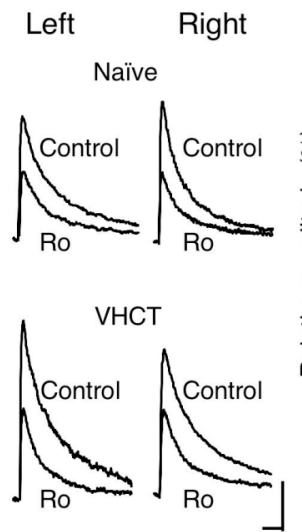

$C$
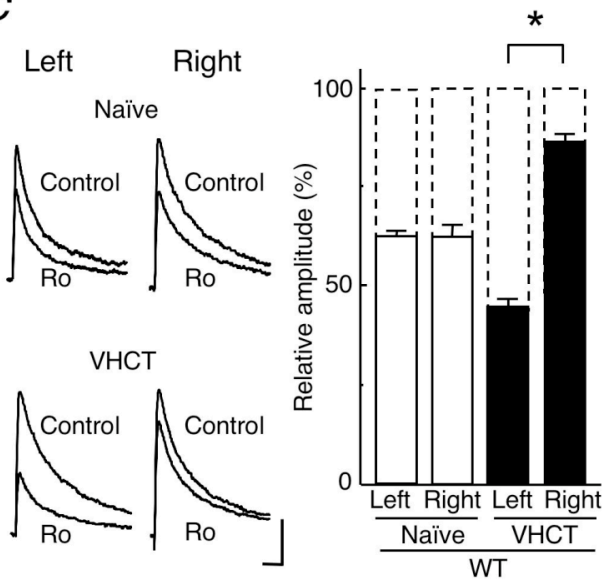

$C$

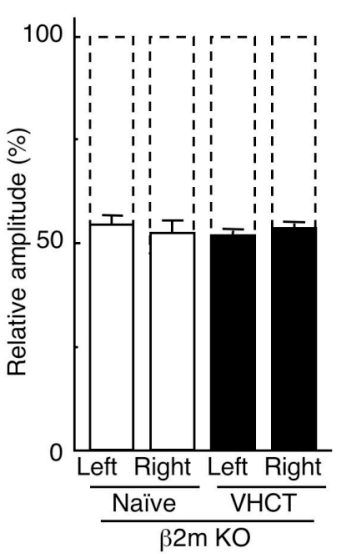
Naïve Control VHCT

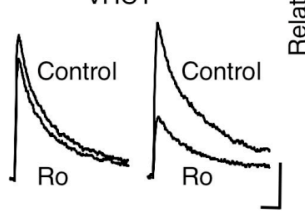<smiles></smiles>

Figure 3. Inhibitory effects of Ro 25-6981 on NMDA EPSCs at CA1 pyramidal neurone synapses.

$A a$, schematic diagrams show synaptic inputs onto the apical dendrites of CA1 pyramidal neurones and the positioning of electrodes. In slices from naïve and VHCT mice, electrical stimuli applied at the stratum radiatum [Stim. (SR)] of area CA1 selectively activated apical synapses. Whole-cell recordings [Rec. (WC)] were made from CA1 pyramidal neurones. Sch, Schaffer collateral fibres; Com, commissural fibres. $A b$, effects of Ro 25-6981 on NMDA EPSCs at CA1 apical synapses in the 
$\beta 2 \mathrm{~m}$-deficient hippocampus $(\beta 2 \mathrm{~m} \mathrm{KO})$. Representative superimposed traces indicate NMDA EPSCs recorded in the absence (Control) and presence of Ro 25-6981 (Ro, 0.6 $\mu \mathrm{M})$. The levels of inhibition were maximal after exposure to Ro 25-6981 for 50 to 60 min. 'Left' and 'Right' indicate recordings from left and right hippocampal slices, respectively. Each trace is the average of five consecutive recordings. Scale bars, $25 \mathrm{pA}$ (vertical) and $100 \mathrm{~ms}$ (horizontal). Relative amplitudes of NMDA EPSCs in the presence of Ro 25-6981 are expressed as percentages of control responses. Error bars represent standard error of the mean $(\mathrm{SEM}) .(\mathrm{n}=7$ each; $\mathrm{P}>0.05$ for all combinations; Student's $t$-test).

Ac, effects of Ro 25-6981 on NMDA EPSCs at CA1 apical synapses in the WT hippocampus. Relative amplitudes of NMDA EPSCs in the presence of Ro 25-6981 are expressed as percentages of control responses. (mean $\pm \mathrm{SEM} ; \mathrm{n}=3$ each; an asterisk indicates $\mathrm{P}<0.05$, absence of an asterisk indicates $\mathrm{P}>0.05)$.

$B a$, schematic diagrams show synaptic inputs onto the basal dendrites of CA1 pyramidal neurones and the positioning of electrodes. Whole-cell recordings [Rec. (WC)] were made from CA1 pyramidal neurones. To activate basal synapses, electrical stimuli were applied at the stratum oriens [Stim. (SO)] of area CA1.

$B b$, effects of Ro 25-6981 on NMDA EPSCs at CA1 basal synapses in the $\beta 2 \mathrm{~m}$-deficient hippocampus. Representative superimposed traces indicate NMDA EPSCs recorded in the absence (Control) and presence of Ro 25-6981 (Ro, $0.6 \mu \mathrm{M})$. 'Left' and 'Right' indicate recordings from left and right hippocampal slices, respectively. Scale bars, $25 \mathrm{pA}$ (vertical) and $100 \mathrm{~ms}$ (horizontal). Relative amplitudes 
of NMDA EPSCs in the presence of Ro 25-6981 are expressed as percentages of control responses. (mean $\pm \mathrm{SEM} ; \mathrm{n}=7$ each; $\mathrm{P}>0.05$ for all combinations).

$B c$, effects of Ro 25-6981 on NMDA EPSCs at CA1 basal synapses in the WT hippocampus. Relative amplitudes of NMDA EPSCs in the presence of Ro 25-6981 are expressed as percentages of control responses. (mean \pm SEM; $n=3$ each; an asterisk indicates $\mathrm{P}<0.05$, absence of an asterisk indicates $\mathrm{P}>0.05)$.

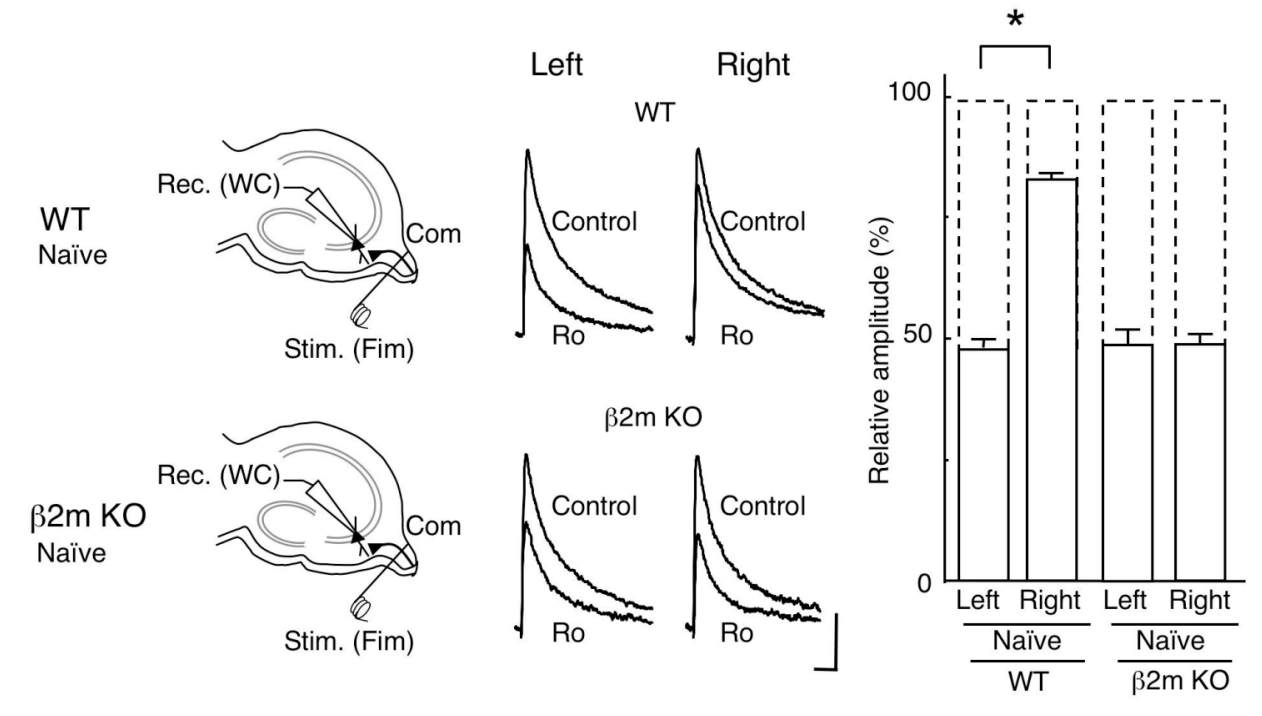

Figure 4. Inhibitory effects of Ro 25-6981 on NMDA EPSCs at basal dendrites of CA3 pyramidal neurones.

Schematic diagrams show synaptic inputs onto the basal dendrites of CA3 pyramidal neurones in WT mice and $\beta 2 \mathrm{~m}$-deficient mice $(\beta 2 \mathrm{~m} \mathrm{KO})$. In slices from naïve mice, 
whole-cell recordings [Rec. (WC)] were made from CA3 pyramidal neurones. A stimulating electrode was placed in the ventral fimbria [Stim. (Fim)] to activate Com fibres (Com). Representative superimposed traces indicate NMDA EPSCs recorded in the absence (Control) and presence of Ro 25-6981 (Ro, $0.6 \mu \mathrm{M})$. 'Left' and 'Right' indicate recordings from left and right hippocampal slices, respectively. Each trace is the average of five consecutive recordings. Scale bars, $25 \mathrm{pA}$ (vertical) and $100 \mathrm{~ms}$ (horizontal). Relative amplitudes of NMDA EPSCs in the presence of Ro 25-6981 are expressed as percentages of control responses (mean $\pm \mathrm{SEM} ; \mathrm{n}=7$ each; an asterisk indicates $\mathrm{P}<0.05$, absence of an asterisk indicates $\mathrm{P}>0.05)$. 


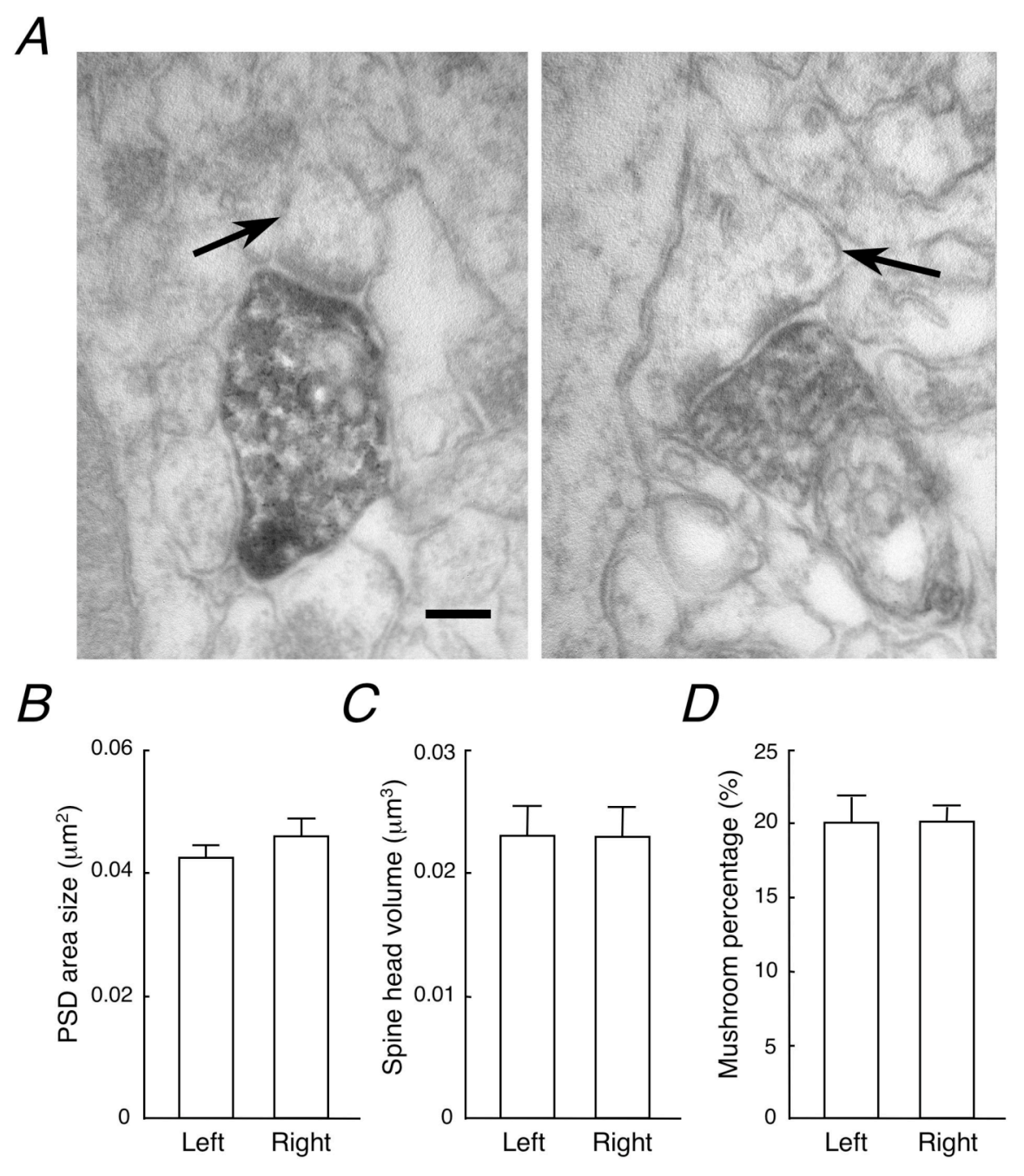

Figure 5. Laterality defects in dendritic spine morphology of the $\beta 2 \mathrm{~m}$-deficient hippocampus.

$A$, electron micrograph of CA1 pyramidal cell synapses in the middle third of the stratum radiatum in the $\beta 2 \mathrm{~m}$-deficient hippocampus. GFP-expressing lentivirus was injected unilaterally into the CA3 pyramidal cell layer. Axons and the terminals of ipsilateral CA3 neurones were heavily labelled for GFP. Arrows indicate thin (left) and mushroom-type (right) spines making contact with GFP-labelled axon terminals. Scale 
bar indicates $300 \mathrm{~nm} . B$ to $D$, average PSD area $(B)$, spine head volume $(C)$, and percentage of mushroom-type spine $(D)$ were compared between the left and right CA1 pyramidal cell synapses of the $\beta 2 \mathrm{~m}$-deficient hippocampus. No significant differences $(\mathrm{P}>0.05)$ in laterality were observed in the three ultrastructural parameters. Error bars represent SEM
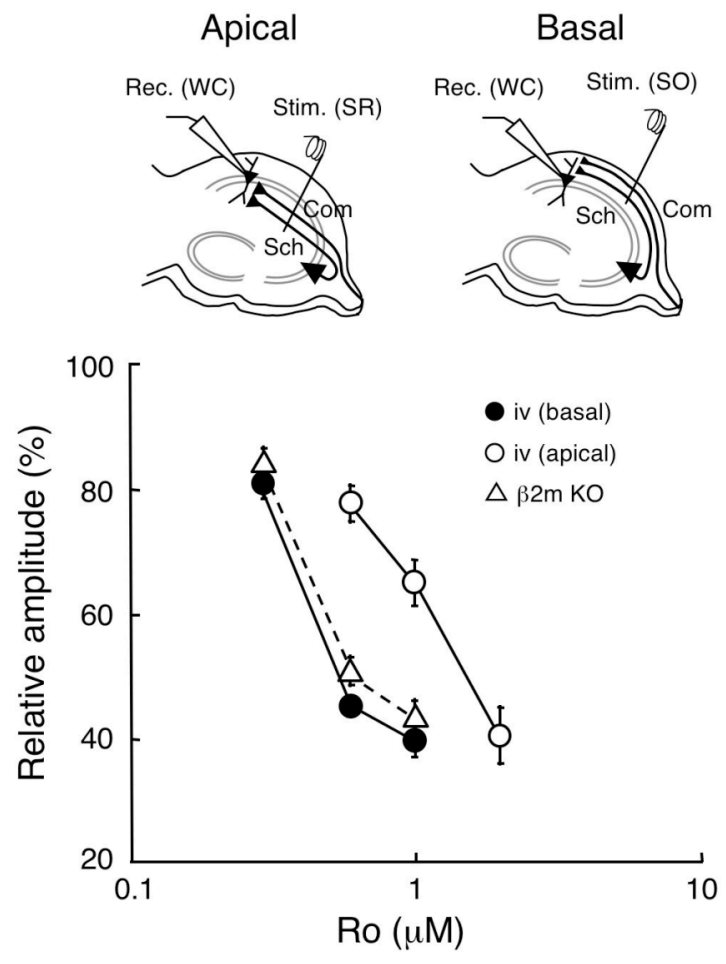

Figure 6. Comparison of concentration dependency of Ro 25-6981 inhibition of NMDA EPSCs between hippocampal synapses of $\beta 2 \mathrm{~m}$-deficient mice and $i v$ mice.

Schematic diagrams show synaptic inputs on the apical and basal dendrites of CA1 pyramidal neurones and the arrangement of electrodes. In hippocampal slices prepared from naïve mice, whole-cell recordings [Rec. (WC)] were made from CA1 pyramidal 
neurones. A stimulating electrode was placed in the stratum radiatum [Stim. (SR)] or in the stratum oriens [Stim. (SO)] of area CA1 to activate apical or basal synapses, respectively. Sch, Schaffer collateral fibres; Com, commissural fibres. NMDA EPSCs were recorded at a holding potential of $+10 \mathrm{mV}$. Relative amplitudes of NMDA EPSCs in the presence of several concentrations of Ro 25-6981 are expressed as percentages of control responses (mean $\pm \mathrm{SEM} ; \mathrm{n}=5$ each). Closed and open circles represent basal $[i v$ (basal)] and apical [iv (apical)] synapses of CA1 pyramidal neurones in the $i v$ mouse hippocampus, respectively. Open triangles represent CA1 apical synapses in the $\beta 2 \mathrm{~m}$-deficient hippocampus ( $\beta 2 \mathrm{~m} \mathrm{KO})$. 

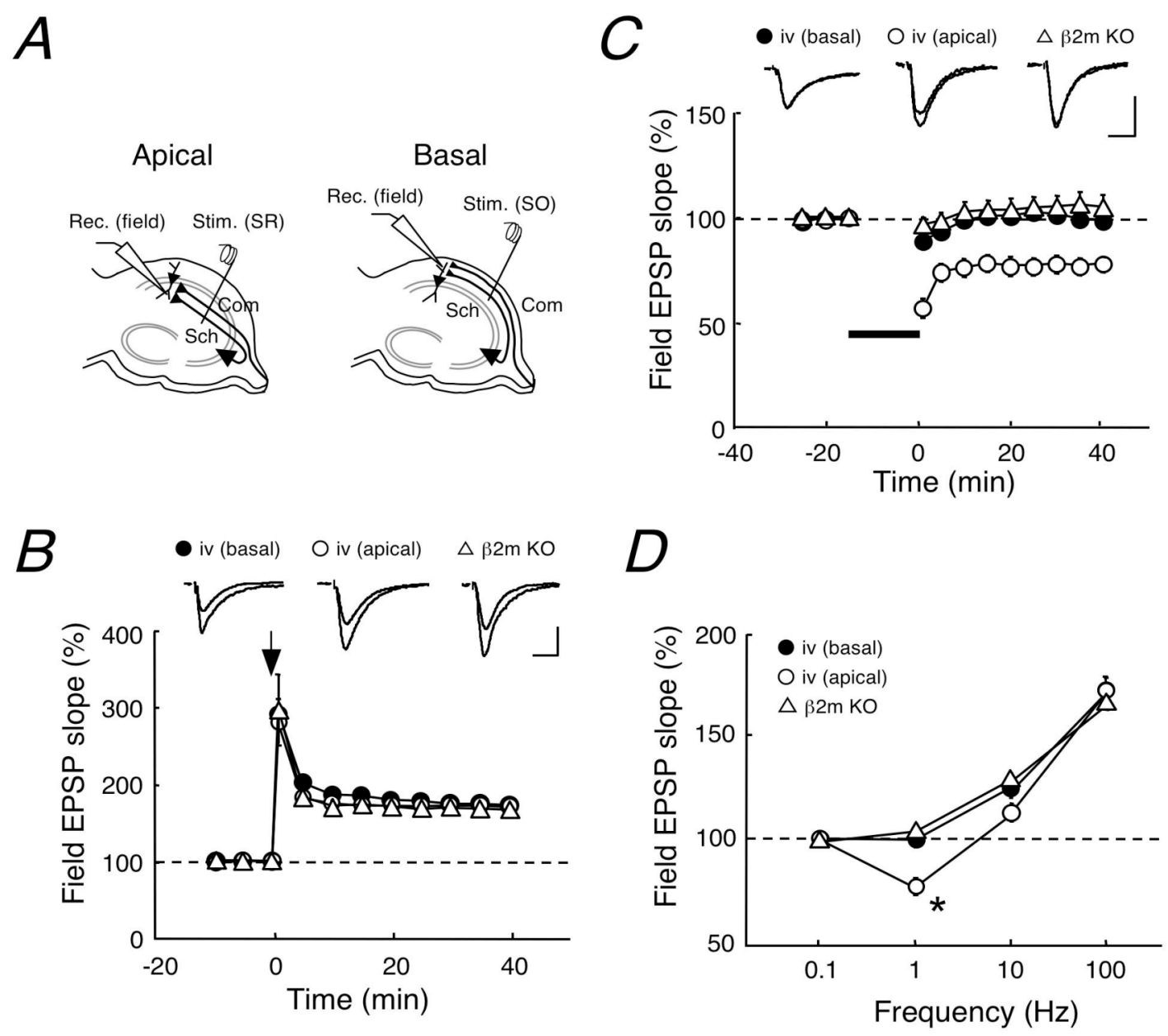

Figure 7. Relationship between synaptic plasticity and stimulation frequency in hippocampal synapses of $\beta 2 \mathrm{~m}$-deficient mice and $i v$ mice.

$A$, schematic diagrams of the arrangement of electrodes for extracellular recording. Using hippocampal slices prepared from naïve mice, field EPSPs were recorded with an extracellular electrode [Rec. (field)] placed either in the stratum radiatum or stratum oriens of area CA1. To activate apical (Apical) or basal dendritic synapses (Basal), a stimulating electrode was placed in the stratum radiatum [Stim. (SR)] or stratum oriens [Stim. (SO)] of area CA1, respectively. $B$, a single tetanic stimulation (100 Hz for $1 \mathrm{sec})$ 
applied at time 0 (arrow) elicited LTPs of the fEPSP slope both in hippocampal slices from $\beta 2 \mathrm{~m}$-deficient mice and $i v$ mice. Closed and open circles represent basal [iv (basal), $\mathrm{n}=11]$ and apical [ $i v$ (apical), $\mathrm{n}=16]$ synapses of CA1 pyramidal neurones in the $i v$ mouse hippocampus, respectively. Open triangles represent CA1 apical synapses in the $\beta 2 \mathrm{~m}$-deficient hippocampus $(\beta 2 \mathrm{~m} \mathrm{KO}, \mathrm{n}=11)$. Symbols and error bars represent means and SEM, respectively. The upper superimposed traces show representative fEPSPs recorded $5 \mathrm{~min}$ before or $40 \mathrm{~min}$ after tetanic stimulation. Scale bars, $0.5 \mathrm{mV}$ (vertical) and $10 \mathrm{~ms}$ (horizontal). $C$, low frequency stimulation (1 Hz for $15 \mathrm{~min}$, thick bar) induced LTD in apical synapses of the $i v$ mouse hippocampus (open circles, $n=14$ ), but not in basal synapses of the iv mouse hippocampus (closed circles, $\mathrm{n}=13$ ) and $\beta 2 \mathrm{~m}$-deficient synapses (open triangles, $\mathrm{n}=11$ ). The upper superimposed traces are representative fEPSPs recorded $5 \mathrm{~min}$ before or $40 \mathrm{~min}$ after low frequency stimulation. Scale bars, $0.5 \mathrm{mV}$ (vertical) and $10 \mathrm{~ms}$ (horizontal). $D$, stimulation-frequency dependency of synaptic plasticity. Relative amplitudes of fEPSP slopes, estimated at 40 min after tetanus, were plotted against stimulation frequencies (mean $\pm \mathrm{SEM}$ ). Points at $0.1 \mathrm{~Hz}$ (test pulse frequency) indicate baseline values (horizontal dashed line). Symbols are the same as those described in $(B)$ and $(C)$. An asterisk indicates $\mathrm{P}<0.05$. 


\section{$\beta 2 \mathrm{~m} \mathrm{KO}$}

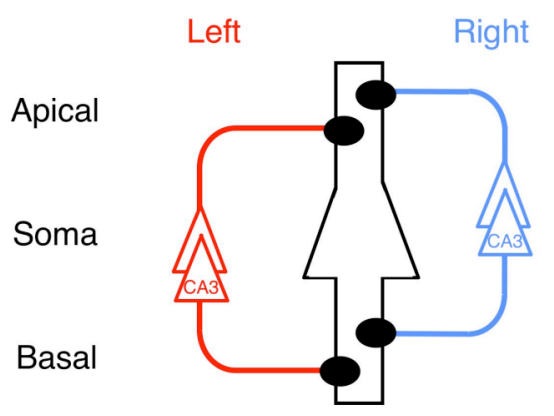

Figure 8 . Asymmetry defects of the $\beta 2 \mathrm{~m}$-deficient mouse hippocampus. A postsynaptic CA1 pyramidal neurone is in the centre, outlined in black, and it represents postsynaptic neurones in both left and right hemispheres. Left and right CA3 pyramidal neurones and their axons are coloured red and blue, respectively. Closed circles represent ' $\varepsilon 2$-dominant' synapses. Note that ' $\varepsilon 2$-nondominant' synapses are lost and circuit asymmetry is collapsed in the $\beta 2 \mathrm{~m}$-deficient hippocampus. 